\title{
Blocking, Unblocking, and Overexpectation of Fear: A Role for Opioid Receptors in the Regulation of Pavlovian Association Formation
}

\author{
Gavan P. McNally, Michael Pigg, and Gabrielle Weidemann \\ University of New South Wales
}

\begin{abstract}
Injection of the opioid receptor antagonist naloxone facilitated acquisition of fear to contextual and auditory conditioned stimuli (CSs) in Experiments 1A and 1B. Experiment 2 showed that prior conditioning to a distinctive context blocked conditioning to an auditory CS. Blocking of CS fear was prevented by administrations of naloxone or increases in footshock intensity. Blocking of CS fear was facilitated by decreases in footshock intensity in a naloxone-reversible manner. Experiment 3 showed that compound conditioning of two CSs, each previously and separately paired with shock, produced overexpectation of fear that was reversed by naloxone. These results are consistent with a role for opioid receptors controlling Pavlovian association formation by regulating the discrepancy $(\lambda-\Sigma V)$ described by R. A. Rescorla and A. R. Wagner (1972).
\end{abstract}

Placed in a novel context (a distinctive chamber) and exposed to pairings of a discrete conditioned stimulus (CS) with brief but aversive footshock (unconditioned stimulus [US]), rats learn about this relation between the context, the CS, and US. They exhibit this learning when reexposed to either the CS or context in a diverse but correlated range of behavioral, endocrine, and autonomic reactions that include freezing, hypoalgesia, potentiated startle, corticosteroid release, and increased arterial blood pressure (Davis, 1992; Fanselow \& LeDoux, 1999; LeDoux, 2000; Maren, 2001). The contents of this learning are commonly viewed in terms of the formation of excitatory associations between a representation of the context, the CS, and a fear motivational system aroused by the aversive US (Konorski, 1967; but see Bolles \& Fanselow, 1980).

Considerable evidence supports the view that these excitatory Pavlovian associations are mediated by glutamatergic neurotransmission in the amygdala. Specifically, this evidence suggests that activation of $N$-methyl-D-aspartate (NMDA) receptors in the amygdala basolateral nucleus $(\mathrm{ABl})$ detects the CS-US conjunction. This activation, in turn, initiates a variety of signal transduction cascades (e.g., $\mathrm{Ca}^{2+}$ and cyclic AMP-dependent signaling) to result in synaptic plasticity and the long-term representation of the CS-US association (for reviews, see Fanselow \& LeDoux, 1999; Maren, 1996, 2001). Among the evidence consistent with this view are lesion data showing that $\mathrm{ABl}$ destruction abolishes fear conditioning (Campeau \& Davis, 1995; Goosens \& Maren, 2001; Sananes \& Davis, 1992), neuropharmacological data showing that infusions of NMDA receptor antagonists prevent the acquisition of fear conditioning (e.g., Campeau, Miserendino, \& Davis, 1992;

Gavan P. McNally, Michael Pigg, and Gabrielle Weidemann, School of Psychology, University of New South Wales, Sydney, New South Wales, Australia.

These experiments were supported by Grant DP0343808 from the Australian Research Council. We thank Fred Westbrook for helpful discussions.

Correspondence concerning this article should be addressed to Gavan P. McNally, School of Psychology, University of New South Wales, Sydney 2052, NSW Australia. E-mail: g.mcnally@unsw.edu.au
Kim, DeCola, Landeira-Fernandez, \& Fanselow, 1991; Miserendino, Sananes, Melia, \& Davis, 1990), and electrophysiologica data showing that fear conditioning produces synaptic plasticity in the $\mathrm{ABl}$ that is correlated with conditioned freezing (e.g., Rogan, Staubli, \& LeDoux, 1997). Moreover, this NMDA-receptordependent plasticity is often further related to Hebb's (1949) learning rule, which states that the increment in learning on a conditioning trial is a function of a constant, activity in a presynaptic neuron, and activity in a postsynaptic neuron.

A difficulty faced when attempting to relate these neurobiological findings to associative learning theory is that learning does not proceed according to the simple CS-US temporal contiguity required for NMDA receptor activation. Temporally contiguous presentations of the CS and US can cause increments; no change; or, indeed, decrements in conditioned fear depending on the associative status of other conditioned stimuli present during those presentations. For example, Kamin (1968) subjected rats to pairings of a light CS and a footshock US. In Stage 2, rats received a compound CS of light + noise followed by the footshock. Kamin's seminal finding was that prior conditioning of the light CS blocked conditioning from accruing to the noise CS, despite the fact that the rats received numerous noise-shock pairings in compound with the light. Kamin $(1968,1969)$ interpreted these findings to mean that conditioning proceeds to the extent to which the US is surprising or unexpected. The rats failed to learn about the added element (the noise CS) in Stage 2 because it was redundant or noninformative with respect to US occurrence. Rescorla (1970) has reported a similarly striking failure of excitatory conditioning using a variant of this blocking design. In Stage 1, Rescorla (1970) trained rats to fear a light CS and a tone CS by pairing them separately with shock. In Stage 2, rats in the experimental group received compound presentations of the light and tone CS with shock, whereas rats in the control groups received either additional tone-shock pairings or no additional training. Rescorla's important observation was that the Stage 2 compound training with the two $\mathrm{CS}$ s reduced the amount of fear provoked by either CS alone on a subsequent test. That is, there was overexpectation of fear in Stage 2 , prompting a reduction in associative strength to each CS that 
was later observed on test. These and related findings encouraged the view that Pavlovian conditioning is determined not just by stimulus temporal contiguity but also by the extent to which conditioning events are predicted or are reliable predictors of their consequences so that only surprising events and their antecedents are learned about.

The neural mechanisms for the blocking and overexpectation of Pavlovian fear are unknown. The endogenous opioid peptides and their receptors are candidates for these mechanisms. The events used in fear conditioning increase the transcriptional activity of opioid neurons in the amygdala (Petrovich, Scicli, Thompson, \& Swanson, 2000). Opioid antagonists facilitate the acquisition (e.g., Fanselow \& Bolles, 1979; Young \& Fanselow, 1992) and prevent the extinction (e.g., McNally \& Westbrook, 2003) of Pavlovian fear conditioning, and targeted deletion of opioid receptor genes enhances fear conditioning (Ragnauth et al., 2001). The present experiments studied this role for opioid receptors in regulating Pavlovian association formation during fear conditioning. The aims of Experiments 1A and 1B were to replicate demonstrations that injection of the opioid receptor antagonist naloxone facilitates the acquisition of Pavlovian fear conditioning. Experiment 2 studied the role of opioid receptors in the blocking of fear conditioning. The question of interest was whether injection of naloxone prior to Stage 2 training would prevent blocking of fear conditioning. Experiment 3 studied the role of opioid receptors in the overexpectation of Pavlovian fear conditioning. The question of interest was whether injection of naloxone prior to Stage 2 training would prevent the overexpectation of fear.

\section{Experiments $1 \mathrm{~A}$ and $1 \mathrm{~B}$}

The aim of Experiments $1 \mathrm{~A}$ and $1 \mathrm{~B}$ was to confirm that subcutaneous injection of the competitive opioid receptor antagonist naloxone facilitates the acquisition of Pavlovian fear conditioning. Experiment 1A studied naloxone modulation of contextual fear conditioning, whereas Experiment $1 \mathrm{~B}$ studied naloxone modulation of auditory CS fear conditioning. Experiments $1 \mathrm{~A}$ and $1 \mathrm{~B}$ both used a single-factor design. Rats were injected with either saline or $3 \mathrm{mg} / \mathrm{kg}$ naloxone prior to contextual (Experiment $1 \mathrm{~A}$ ) or auditory CS (Experiment 1B) fear conditioning. All rats were then tested for their fear reactions to the context (Experiment 1A) or the auditory CS (Experiment 1B) in the absence of naloxone.

\section{Method}

\section{Subjects}

The subjects were 32 experimentally naive, adult male Wistar rats (280-350 g) obtained from a commercial supplier (Gore Hill Research Laboratories, Sydney, Australia). There were 16 rats in Experiment $1 \mathrm{~A}$ and 16 rats in Experiment 1B. After arrival, rats were housed in groups of 6-8 in plastic cages maintained on a 12-hr light-dark cycle (lights on at 7 a.m.) and were allowed access to water and food ad libitum. The rats were handled (1-2 min per rat per day) for 3 days to habituate them to the experimenter. There were 8 rats per group. The procedures used in these experiments were conducted in accordance with the Guidelines for Ethical Conduct in the Care and Use of Animals (American Psychological Association) and were approved by the Animal Care and Ethics Committee at The University of New South Wales.

\section{Apparatus}

Experiment 1A. Conditioning and testing were conducted in a set of four identical chambers $(24 \mathrm{~cm}$ long $\times 30 \mathrm{~cm}$ wide $\times 21 \mathrm{~cm}$ high $)$. The front and rear walls of these chambers as well as the hinged lid were constructed of clear Perspex, and the end walls were made of stainless steel. The floor in each chamber consisted of stainless steel rods, $4 \mathrm{~mm}$ in diameter, spaced $15 \mathrm{~mm}$ apart (center to center). Each chamber stood $2 \mathrm{~cm}$ above a tray of paper pellet bedding (Fibrecycle, Mudgeeraba, Australia). The chambers were cleaned with water, and the bedding underneath the chambers was changed between rats. These four chambers were located individually within sound-attenuating boxes that were painted white. The boxes were illuminated by a 24-W light mounted on the rear wall. The US was a 1-s, 0.4-mA unscrambled AC 50-Hz shock from a constant-current generator that was delivered to the floor of each chamber. The current available to each floor could be adjusted using an in-line milliampere meter. Digital video cameras were mounted on the rear wall of each box and connected to a digital multiplexer in an adjacent room that, in turn, was connected to a video recorder. The stimuli used for conditioning were controlled by computer (LabView; National Instruments, Austin, TX).

Experiment $1 B$. Conditioning and testing were conducted in two different sets of four identical chambers. The set of chambers used for conditioning were identical to those described for Experiment 1A. The second set of chambers, used for test, differed from the conditioning chambers in size $(21 \mathrm{~cm}$ long $\times 23 \mathrm{~cm}$ wide $\times 20 \mathrm{~cm} \mathrm{high})$ and construction. The front and rear walls of these chambers as well as the hinged lid were constructed of clear Perspex, and the end walls were made of stainless steel. The floor in each chamber consisted of stainless steel rods, $3 \mathrm{~mm}$ in diameter, spaced $12 \mathrm{~mm}$ apart (center to center). Each chamber stood $2 \mathrm{~cm}$ above a tray of paper pellet bedding that was changed between rats. These test chambers were located in different soundattenuating chambers that were painted black and were illuminated by a 24-W red light mounted on the rear wall. The CS was a 74-dB (A scale), 20-Hz clicker delivered through speakers mounted in the ceiling of each box. All other apparatus was that described for Experiment 1A.

\section{Drugs}

Naloxone hydrochloride (Sigma Chemical, St Louis, MO) was dissolved in $0.9 \%$ (wt/vol) nonpyrogenic saline to obtain a concentration of $3 \mathrm{mg} / \mathrm{ml}$. This $0.9 \%$ non pyrogenic saline was used for control injections. All injections were subcutaneous in the dorsal neck region, in a volume of 1 $\mathrm{ml} / \mathrm{kg}$.

\section{Procedure}

Experiment 1A. Across Days 1-5 of the experiment, rats were transported to the laboratory and injected with saline or naloxone according to group allocation. Ten minutes later, they were placed in the conditioning chambers. Two minutes later, the 1-s US was presented. Rats remained in the chambers for a further $30 \mathrm{~s}$ before being returned to their home cage. On Days 6 and 7, all rats were tested for their fear reactions to the context. Rats were transported to the laboratory and placed in the conditioning context for $10 \mathrm{~min}$.

Experiment $1 B$. Across Days 1-5 of the experiment, rats were transported to the laboratory and injected with saline or naloxone according to group allocation. Ten minutes later, they were placed in the conditioning chambers. One minute and fifty seconds later, the 10-s 74-dB CS was presented and coterminated with delivery of the 1-s US. Rats remained in the chambers for a further $30 \mathrm{~s}$ before being returned to their home cage. On Days 6 and 7, all rats were tested for their fear reactions to the auditory CS. Rats were transported to the laboratory and placed in the test chambers for $8 \mathrm{~min}$. The auditory CS was then presented for $8 \mathrm{~min}$. 


\section{Statistics}

Performance during conditioning and test was videotaped. The rats were subsequently scored, every $4 \mathrm{~s}$, as either freezing (defined as the absence of all movement other than that required for breathing) or not freezing. In Experiment $1 \mathrm{~A}$, rats were scored as freezing during the 2 min that immediately preceded each US presentation during conditioning and were also scored on test. In Experiment 1B rats were scored only on test. The percentage of these observations scored as freezing was then calculated. The videotapes were scored by two observers, one of whom was unaware of group allocation. The interrater reliabilities, that is, the correlation between each observer's ratings of the percentage of observations scored as freezing, consistently exceeded .90 in this and remaining experiments. The data were analyzed by means of a planned orthogonal contrast testing procedure adopting a multivariate approach to repeated measures where necessary (O'Brien \& Kaiser, 1985). The Type I error rate was controlled at 0.05 for each contrast tested.

\section{Results}

The mean $( \pm S E M)$ percentage of observations scored as freezing during conditioning and test of Experiment 1A are shown in Figure 1. Inspection of Figure 1 suggests that naloxone facilitated the acquisition of contextual fear conditioning as indexed by higher levels of freezing during the 2 min preceding each US on conditioning and during the 2 days of test. The statistical analysis confirmed these observations.

During conditioning, there were significantly greater overall levels of freezing among naloxone-treated rats as compared to saline-treated rats, $F(1,14)=9.9, p<.01$. The levels of freezing showed a significant linear increase across days, $F(1,14)=393.9$, $p<.01$. However, this linear increase across days did not interact significantly with any differences between groups, $F(1,14)=1.9$, $p>$.05. In other words, naloxone increased overall levels of freezing during contextual fear conditioning without significantly affecting the rate at which conditioning accrued to the context.

During the 10-min test on Day 6 (Test 1), there was significantly greater overall levels of freezing among naloxone-treated rats as compared to saline-treated rats, $F(1,14)=12.9, p<.01$. Freezing decreased significantly in a linear fashion across the 10-min test, $F(1,14)=19.2, p<.01$. Moreover, this decrease was significantly greater among the saline-treated rats as compared to the naloxone-treated rats, $F(1,14)=9.4, p<.01$. During the 10 -min test on Day 7 (Test 2), there were significantly greater overall levels of freezing among naloxone-treated rats as compared to saline-treated rats, $F(1,14)=8.1, p=.01$. Freezing decreased significantly in a linear fashion across the 10 -min test, $F(1,14)=$ $12.5, p<.01$. However, there was no difference between the naloxone- and saline-treated rats in this decrease, $F(1,14)<1$, $p>.05$.

The mean $( \pm S E M)$ percentage of observations scored as freezing during the 2 min immediately preceding CS presentation and during the CS presentation on test in Experiment 1B are shown in Figure 2. Inspection of the figure suggests that naloxone facilitated the acquisition of CS fear conditioning as indexed by higher levels of freezing across test. The statistical analysis confirmed these observations.

During the 2 min pre-CS period on Day 6 (Test 1), rats that were conditioned under the influence of naloxone showed significantly greater levels of freezing than rats conditioned under saline, $F(1$, $14)=12.4, p<.01$. During the 8-min CS presentation on Day 6 (Test 1), there was no overall significant difference between levels of freezing among naloxone-treated rats conditioned and salinetreated rats, $F(1,14)=1.6, p>.05$. There was no overall linear decrease in freezing across the 8-min test, $F(1,14)=3.8, p>.05$. However, there was an interaction between these two contrasts, $F(1,14)=6.9, p=.02$, so that freezing among rats conditioned under the influence of saline decreased significantly more than among rats conditioned under the influence of naloxone. During the 2-min pre-CS period on Day 7 (Test 2), rats conditioned under the influence of naloxone did not significantly differ in levels of freezing from rats conditioned under saline, $F(1,14)<1, p>.05$. During the 8-min CS presentation on Day 7 (Test 2), there was an overall significant difference between levels of freezing among naloxone-treated rats and saline-treated rats, $F(1,14)=8.6, p=$ .01 , such that the rats conditioned under naloxone showed signif-

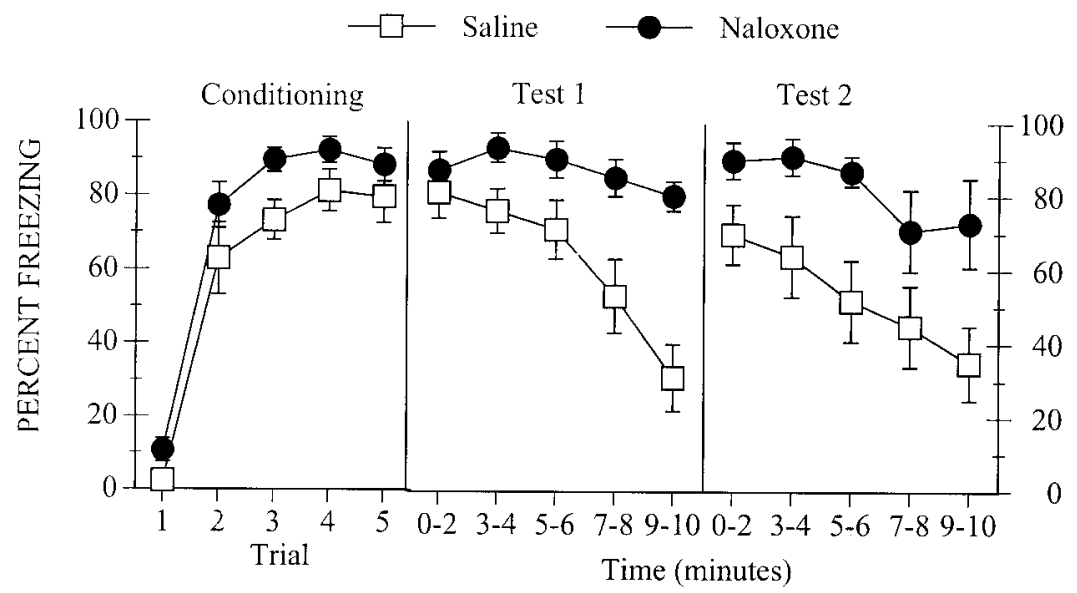

Figure 1. Naloxone facilitates the acquisition of contextual fear conditioning. Mean ( \pm SEM) levels of context freezing during conditioning, Test 1, and Test 2 in Experiment 1A. Rats received context-shock pairings under the influence of $3 \mathrm{mg} / \mathrm{kg}$ naloxone or saline and were later tested for freezing to the context. 


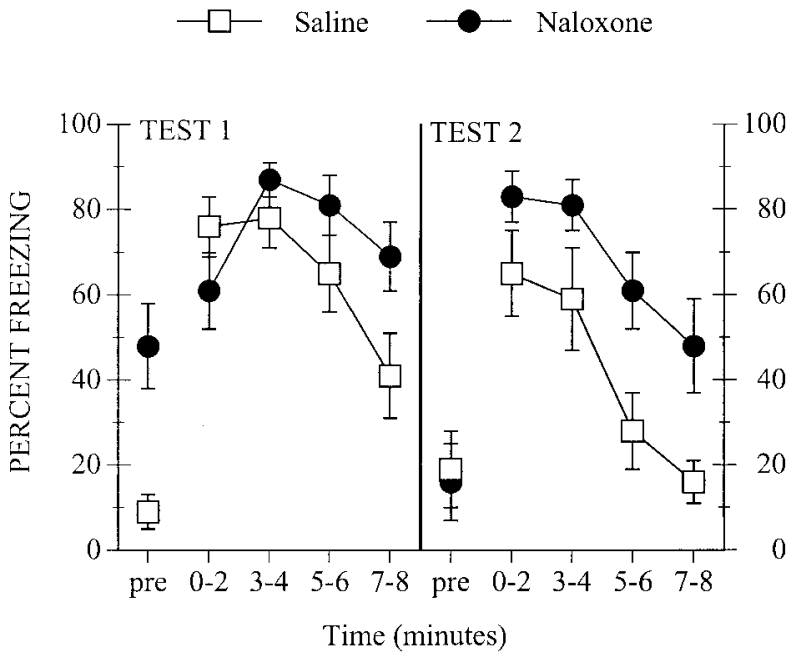

Figure 2. Naloxone facilitates the acquisition of auditory conditioned stimulus (CS) fear conditioning. Mean ( \pm SEM) levels of CS freezing during Test 1 and Test 2 in Experiment 1B. Rats received CS-shock pairings under the influence of $3 \mathrm{mg} / \mathrm{kg}$ naloxone or saline and were later tested for freezing to the context. pre $=$ before CS presentation.

icantly more freezing than the rats conditioned under saline. There was an overall linear decrease in freezing across the 8-min test, $F(1,14)=32.4, p<.05$. However, there was no interaction between these two contrasts, $F(1,14)=1.1, p>.05$.

\section{Discussion}

This experiment confirms that opioid receptors regulate the acquisition of Pavlovian fear conditioning as indexed either by contextual fear conditioning or by conditioning to a discrete auditory CS. Specifically, this experiment shows that an injection of the competitive opioid receptor antagonist naloxone facilitates the acquisition of contextual fear conditioning (e.g., Fanselow \& Bolles, 1979; Young \& Fanselow, 1992), and extends this observation to show a similar facilitation of CS fear conditioning. It is worth emphasizing that although naloxone-treated rats showed significantly greater levels of pre-CS freezing during Test 1 in Experiment 1B, this difference in levels of pre-CS freezing cannot explain the facilitation of CS freezing. Specifically, during Test 2 there were significant differences between naloxone- and salinetreated rats in levels of CS freezing, but no differences between these groups in levels of pre-CS freezing. In other words, the facilitation of the acquisition of CS freezing by naloxone was observed independently of the levels of pre-CS freezing in the test context. These differences between naloxone- and saline-treated rats cannot be attributed to state-dependent learning because statedependent learning predicts a generalization decrement as a consequence of the shift in internal state from conditioning (under naloxone) to test (under saline). The results of Experiments $1 \mathrm{~A}$ and $1 \mathrm{~B}$ are inconsistent with this possibility. Instead, these results are consistent with a role for opioid receptors in regulating the acquisition of Pavlovian fear conditioning but leave unanswered the question of how this regulation might be achieved (see General Discussion).

\section{Experiment 2}

In a conditioned suppression preparation, Kamin (1968) subjected rats to 16 presentations of a light CS followed by a footshock US. In Stage 2, rats received a compound stimulus of light + noise followed by the footshock US. Kamin's seminal finding was that prior conditioning of the light CS blocked conditioning from accruing to the noise CS as compared to a control group that received no training in Stage 1 and the compound training in Stage 2. Kamin also reported that blocking was abolished when the intensity of footshock was increased from Stage 1 to Stage 2. Thus, experimental rats that had received 16 pairings of a noise with a $1-\mathrm{mA}$ footshock in Stage 1 and 8 pairings of the light-noise compound with a 4-mA footshock in Stage 2 showed robust conditioning to the added element (the light) as compared to control rats for which shock intensity was not varied between Stages 1 and 2. Blocking and unblocking encouraged the view that conditioning proceeds as a function of variations in the effectiveness of the shock US, so that only surprising USs are learned about (Rescorla \& Wagner, 1972; Wagner \& Rescorla, 1972).

Although it is widely accepted that blocking of conditioned fear can be abolished by increases in US intensity during Stage 2, there is conflicting evidence regarding the influence on blocking of fear produced by downshifts in US intensity during Stage 2. Using conditioned suppression, Dickinson, Hall, and Mackintosh (1976) subjected rats to 12 pairings of a clicker CS with two footshock USs. They then arranged a compound stimulus of clicker + light to signal a single footshock US on eight occasions in Stage 2. Their important finding was that the decrease in US number from Stage 1 to Stage 2 produced as much evidence for unblocking of conditioned fear as did an increase in shock number from Stage 1 to Stage 2. Unblocking by decreases in US number is inconsistent with the view that conditioning proceeds as a function of variations in the effectiveness of the US. Instead, it encouraged the view that conditioning proceeds as a function of variations in CS processing, so that only the antecedents (the CS) to surprising events (the reduction in US number) are learned about (e.g., Mackintosh, 1975; Pearce \& Hall, 1980). By contrast, Wagner, Mazur, Donegan, and Pfautz (1980) failed to find any such evidence for unblocking. In Stage 1, Wagner et al. trained rats on one CS (A) with a high-intensity US and another CS (B) with a low-intensity US. During Stage 2, a third CS (X) was reinforced in compound with A or B and the low-intensity US. Using this variant of an unblocking design, Wagner et al. detected no evidence for unblocking of $\mathrm{X}$ and, indeed, provided evidence that the added element in such an arrangement acquires significant inhibitory properties.

Experiment 2 had two aims. The first was to determine whether blocking of Pavlovian fear conditioning was mediated by the release of endogenous opioid peptides, and therefore could be prevented when rats were subject to Stage 2 training under the influence of naloxone. The second aim was to determine the influence on blocking of variations in US intensity between Stage 1 and Stage 2. The design of Experiment 2 is shown in Table 1. Rats were allocated to 1 of 10 groups. In Stage 1, rats in Group Block, Unblock Up, and Unblock Down each received five shockreinforced ( $1 \mathrm{~s}, 0.6 \mathrm{~mA}$ ) exposures to a distinctive context. Rats in Group Control Same received five nonreinforced exposures to the context. In Stage 2, all groups received two clicker-shock pairings. 
Table 1

Design of Experiment 2

\begin{tabular}{llll}
\hline \multicolumn{1}{c}{ Group } & \multicolumn{1}{c}{ Stage 1} & \multicolumn{1}{c}{ Stage 2} & Test \\
\hline Control Same-Saline & Context only & Saline/context + CS-0.6 mA & CS \\
Control Same-Naloxone & Context only & Naloxone/context + CS-0.6 mA & CS \\
Block-Saline & Context-0.6 mA & Saline/context + CS-0.6 mA & CS \\
Block-Naloxone & Context-0.6 mA & Naloxone/context + CS-0.6 mA & CS \\
Unblock Up-Saline & Context-0.6 $\mathrm{mA}$ & Saline/context + CS-0.9 mA & CS \\
Unblock Up-Naloxone & Context-0.6 mA & Naloxone/context + CS-0.9 mA & CS \\
Unblock Down-Saline & Context-0.6 mA & Saline/context + CS-0.3 mA & CS \\
Unblock Down-Naloxone & Context-0.6 mA & Naloxone/context + CS-0.3 mA & CS \\
Control Down-Saline & Context only & Saline/context + CS-0.3 mA & CS \\
Control Down-Naloxone & Context only & Naloxone/context + CS-0.3 mA & CS \\
\hline
\end{tabular}

Note. $\quad \mathrm{CS}=$ conditioned stimulus.

For rats in Groups Control Same and Control Block, the shock was $1 \mathrm{~s}$ in duration and $0.6 \mathrm{~mA}$ intensity. For rats in Group Unblock Up, the shock was $1 \mathrm{~s}$ in duration and $0.9 \mathrm{~mA}$ intensity. For rats in Groups Control Down and Unblock Down, the shock was $1 \mathrm{~s}$ in duration and $0.3 \mathrm{~mA}$ intensity. For half the rats in each of these groups, Stage 2 conditioning occurred under the influence of naloxone, whereas for the remainder, this conditioning occurred under the influence of saline. Rats in Group Control Down received five nonreinforced exposures to the context during Stage 1 and two shocked exposures to the auditory CS in Stage 2. The intensity of this shock was $0.3 \mathrm{~mA}$. All rats were tested for their fear reactions to the auditory CS in a second context.

\section{Method}

\section{Subjects and Apparatus}

The subjects were 80 experimentally naive, adult male Wistar rats (280-350 g) obtained from the same commercial supplier and maintained under the same conditions as described for Experiments 1A and 1B. The apparatus was that described for Experiments 1A and 1B. Conditioning took place in the white sound-attenuating chambers, whereas test took place in the black sound-attenuating chambers described previously. There were 8 rats per group.

\section{Procedure}

Stage 1. Stage 1 training lasted for 5 days. Each day, rats were transported to the laboratory and placed in the conditioning context for 10 min. For rats in all groups, except Control Same and Control Down, a single, 1-s, 0.6-mA footshock was delivered at $5 \mathrm{~min}$. All groups also received 10 min nonreinforced exposures to the test context on Days 3, 4, and 5. These exposures occurred $6 \mathrm{hr}$ after conditioning. This was done to reduce the generalization of any fear from the training context to the test context.

Stage 2. Stage 2 training lasted for 2 days. Each day, rats were transported to the laboratory and placed in the conditioning context for 10 min. For rats in all groups the 10-s, 74-dB clicker was presented after 4 min and $50 \mathrm{~s}$, and this presentation coterminated with shock. This shock was $1 \mathrm{~s}$ in duration and was $0.3,0.6$, or $0.9 \mathrm{~mA}$ intensity according to group allocations. Rats received an additional 10-min exposure to the test context between Stage 2 and test to reduce the generalization of any fear from the training context to the test context.

Test. All rats were tested for their fear reactions (freezing) to the auditory CS across 3 days in the second context. Each day, rats were transported to the laboratory and placed in the test context. The auditory CS was presented $10 \mathrm{~min}$ later for $8 \mathrm{~min}$.

\section{Results}

There were minimal to moderate levels of freezing in the 2-min pre CS period $(M \pm S E M$ : Control-Saline, $26.9 \% \pm 4.0 \%$; Control-Naloxone, $17.0 \% \pm 3.6 \%$; Block-Saline, $19.0 \% \pm 4.3 \%$; Block-Naloxone, $26.9 \% \pm 4.9 \%$; Unblock Up-Saline, $31 \% \pm$ 7.0\%; Unblock Up-Naloxone, $33.0 \% \pm 5.7 \%$; Unblock DownSaline, $19.9 \% \pm 3.7 \%$; Unblock Down-Naloxone, $31.8 \% \pm 5.9 \%$; Control Down-Saline, $13.5 \% \pm 3.5 \%$; Control Down-Naloxone, $22.8 \% \pm 3.5 \%)$. There was evidence for conditioning to the auditory CS, as shown by a significant increase in freezing following presentations of the CS as compared to the pre-CS period, $F(1,70)=304.9, p<.01$.

The mean $( \pm S E M)$ percentage of observations spent freezing during CS presentations on test are shown in Figure 3. There was evidence for context blocking of CS fear conditioning because Group Block-Saline showed significantly less freezing than Group Control-Saline, $F(1,70)=6.3, p=.01$. There was evidence for the unblocking of CS fear by the increase in shock intensity

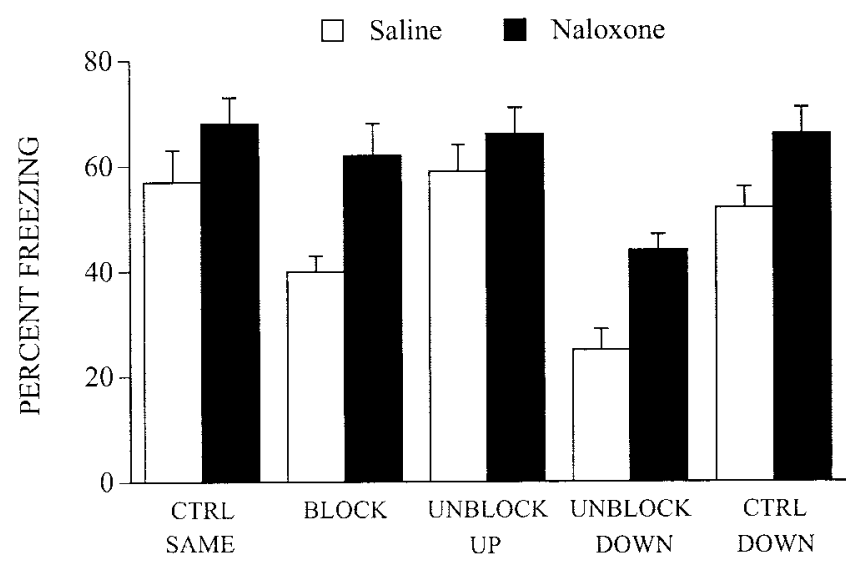

Figure 3. Naloxone prevents the blocking of Pavlovian fear conditioning. Mean ( $\pm S E M$ ) levels of conditioned stimulus freezing on test in Experiment 2. Rats received Stage 2 conditioning under the influence of $3 \mathrm{mg} / \mathrm{kg}$ naloxone or saline. For experimental design, see Table 1. CTRL $=$ control. 
because Group Unblock Up-Saline showed significantly more freezing than Group Block-Saline, $F(1,70)=8.4, p<.01$. There was no evidence for the unblocking of CS freezing by the decrease in shock intensity. Group Unblock Down-Saline showed significantly less freezing than Group Block-Saline, $F(1,70)=4.7, p=$ .03. Moreover, Group Unblock Down-Saline showed significantly less freezing than Group Control-Down, $F(1,70)=15.5, p<.01$.

Naloxone prevented the blocking of CS fear conditioning, as shown by significantly higher levels of freezing in Group BlockNaloxone than in Group Block-Saline, $F(1,70)=11.8, p<.01$. Naloxone did not significantly increase CS fear conditioning in Group Control-Naloxone as compared to Group Control-Saline, $F(1,70)=3.2, p>.05$, nor did naloxone significantly increase CS fear conditioning in Group Unblock Up-Naloxone as compared to Group Unblock Up-Saline, $F(1,70)=1.1, p>.05$. This result is thus different from that obtained in Experiment 1B but might easily be explained by the procedural differences between the experiments. Naloxone did significantly increase freezing among Group Unblock Down-Naloxone as compared to Group Unblock Down-Saline, $F(1,70)=7.7, p<.01$, but this modulation of freezing simply returned freezing to the levels observed among Group Control Down-Saline. Finally, naloxone significantly increased freezing among Group Control Down-Naloxone as compared to Group Control Down-Saline, $F(1,70)=5.0, p<.05$ (consistent with the effects of naloxone in Experiment 1B).

These differences between groups in CS freezing cannot be attributed to differences between groups in pre-CS freezing because none of these comparisons tested between groups on pre-CS levels of freezing reached statistical significance, largest $F(1$, $70)=4.0, p>.05$; smallest $F(1,70)=0.0, p>.05$.

\section{Discussion}

This experiment replicates three important findings. First, there was evidence for the blocking of CS fear conditioning by prior contextual conditioning. Second, there was evidence that blocking could be prevented by an increase in US intensity during Stage 2. Third, there was no evidence for unblocking of CS fear conditioning by a decrease in US intensity during Stage 2 training. In fact, less conditioning accrued to the CS in rats conditioned with the high-intensity US as compared to a control group conditioned with the low-intensity US. This is consistent with the results of Wagner et al. (1980) but stands in contrast to the results of Dickinson et al. (1976). The factors that determine whether or not a reduction in the US will promote unblocking (i.e., excitatory) or inhibitory conditioning are unclear. However, evidence for inhibitory conditioning with reductions in the US has typically been obtained from designs that manipulate US intensity or concentration, whereas evidence for excitatory conditioning has been derived from designs that manipulate the number or sequence of reinforcers (for review of the factors influencing unblocking, see Holland, 1988). Regardless, this experiment has shown for the first time that the blocking of CS fear by prior context conditioning is mediated, at least in part, by opioid receptors because it was prevented by injection of naloxone.

\section{Experiment 3}

Rescorla (1970) used a variation of the blocking design to reveal significant reductions in conditioned responding to a CS, previously paired with a footshock US, when that CS was conditioned in compound with another CS, also previously paired with a footshock US. Rescorla trained rats to fear a light CS and a tone CS by pairing them separately with shock. In Stage 2, rats in the experimental group received compound presentations of the light and tone CS with shock, whereas rats in the control groups received either additional tone-shock pairings or no additional training. Rescorla's critical observation was that Stage 2 compound training of the two CSs reduced the amount of fear later provoked by either CS (i.e., there was overexpectation of fear). This reduction in conditioned responding is robust against variations in parameters, species, and conditioning preparations (Kamin \& Gaioni, 1974; Khallad \& Moore, 1996; Kremer, 1978; Lattal \& Nakajima, 1998; Wagner, 1971) and is particularly problematic for accounts of conditioning that invoke simple CS-US temporal contiguity or the consequent NMDA receptor activation as mechanisms for learning (e.g., Hebb, 1949; Rogan et al., 1997; Tsien, 2000). The performance of Group Unblock Down-Saline in Experiment 2 was similar to overexpectation. Put simply, when the Stage 2 compound CS was arranged to signal a weaker US than was used in Stage 1, significantly less conditioning accrued to the $\mathrm{CS}$ in that group compared to the relevant control group. Administrations of naloxone prior to Stage 2 training prevented this decrement.

The aim of Experiment 3 was to study the role of opioid receptors in producing the overexpectation of Pavlovian fear conditioning. Rats were allocated to one of four groups (see Table 2). During Stage 1 training, all rats received separate pairings of a flashing light CS with shock and a clicker CS with shock. During Stage 2, rats in the experimental groups received compound presentations of the flashing light and clicker paired with shock. During Stage 2, rats in the control group were simply transported to the laboratory and handled. For half the rats in the experimental and control groups, Stage 2 training occurred after subcutaneous injection of naloxone, whereas for the remainder this training occurred after subcutaneous injection of saline. The question of interest was whether injection naloxone during Stage 2 would prevent the overexpectation of Pavlovian fear.

Table 2

Design of Experiment 3

\begin{tabular}{lccr}
\hline \multicolumn{1}{c}{ Group } & \multicolumn{1}{c}{ Stage 1 } & Stage 2 & Test \\
\hline Control-Saline & Clicker-shock, light-shock & Saline & Clicker \\
Control-Naloxone & Clicker-shock, light-shock & Naloxone & Clicker \\
Overexpect-Saline & Clicker-shock, light-shock & Saline/clicker + light-shock & Clicker \\
Overexpect-Naloxone & Clicker-shock, light-shock & Naloxone/clicker + light-shock & Clicker \\
\hline
\end{tabular}




\section{Method}

\section{Subjects and Apparatus}

The subjects were 32 experimentally naive, adult male Wistar rats (280-350 g) obtained from the same commercial supplier and maintained under the same conditions described previously. The apparatus was that described previously. Conditioning took place in the white soundattenuating chambers, and test took place in the black sound-attenuating chambers. There were 8 rats per group.

\section{Procedure}

Stage 1. Stage 1 training lasted for 6 days. Each day, rats were transported to the laboratory and placed in the conditioning context for 20 min. The boxes were illuminated by a $24-\mathrm{W}$ red light. A single, $1-\mathrm{s}$, 0.5 -mA footshock was delivered at $10 \mathrm{~min}$. On Days 1,3 , and 5, this footshock was signaled by a 30-s 74-dB, 20-Hz clicker. On Days 2, 4, and 6 , this footshock was signaled by a 30 -s flashing $(1 \mathrm{~Hz})$ of a $4-\mathrm{W}$ white fluorescent light mounted on the ceiling of each sound-attenuating chamber. Six hours after conditioning on Days 5 and 6, rats received additional 20 -min nonreinforced exposures to the conditioning context. This was done to reduce the levels of context conditioning.

Stage 2. Stage 2 training lasted for 2 days. Each day, rats in the experimental groups (Groups Overexpect) were transported to the laboratory and injected with saline or naloxone. Ten minutes later, they were placed in the conditioning context for $20 \mathrm{~min}$. They received two 30-s presentations of the light-clicker compound coterminating with a 1-s, $0.5-\mathrm{mA}$ footshock. The interval between compound presentations was 10 min. Rats in the control groups were transported to the laboratory and injected with saline or naloxone. Ten minutes later they were briefly handled. Rats in both groups received two additional 10-min exposures to the test context between Stage 2 and test. This was done to reduce the generalization of any fear from the training context to the test context.

Test. All rats were tested for their fear reactions (freezing) to the clicker in a single session. This test consisted of four nonreinforced 30-s presentations of the clicker spaced $4 \mathrm{~min}$ apart. Rats were tested with the clicker in order to aid comparison with the results of Experiments 1A, 1B, and 2 .

\section{Results}

The mean $( \pm S E M)$ percentage of observations spent freezing by groups during the last CS presentations in Stage 1, during the 2 days of Stage 2 training, and on test are shown in Figure 4. Inspection of the figure shows that all groups showed robust conditioning to both the clicker and light CS at the end of Stage 1 training. Stage 2 training was associated with a reduction in freezing to the compound CS among Group Overexpect-Saline as compared to Group Overexpect-Naloxone. Freezing on test revealed evidence for overexpectation because levels of freezing were lower among Group Overexpect-Saline compared to Group Control-Saline. Moreover, naloxone prevented this overexpectation of fear conditioning because Group Overexpect-Naloxone did not differ from Group Control-Saline.

Freezing during the 2-min pre-CS period for Groups Overexpect-Saline and Overexpect-Naloxone was lost as a result of a failure of the video recorder. However, there were very low levels of freezing during this period for rats in Groups ControlSaline $(M=2.1 \%)$ and Control-Naloxone $(M=2.5 \%)$, and these groups did not differ significantly, $F(1,14)<1, p>.05$. Because we had designed the experiment specifically to reduce the generalization of fear from the conditioning context to the test context,
Saline

Naloxone

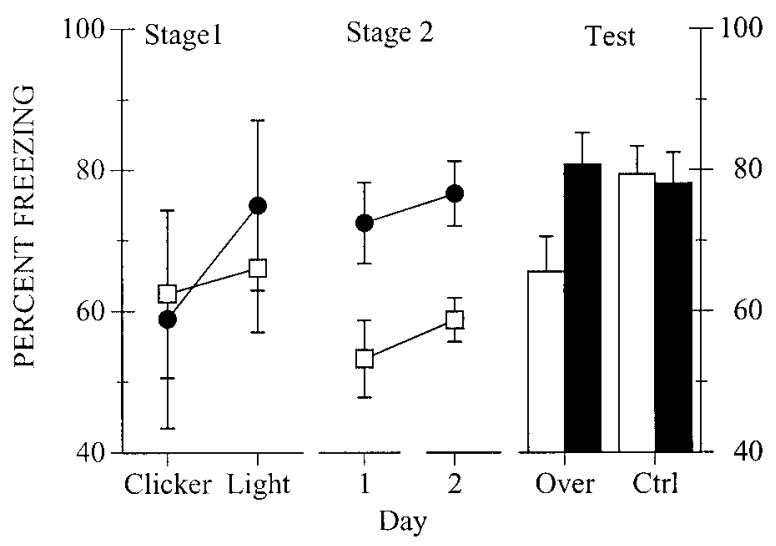

Figure 4. Naloxone prevents the overexpectation of Pavlovian fear conditioning. Mean $( \pm S E M)$ levels of conditioned stimulus (CS) freezing on test in Experiment 3. During Stage 1, rats received separate pairings of a light + clicker CS with shock. During Stage 2, rats in Groups Over received compound light + clicker pairings with shock. Rats received Stage 2 conditioning under the influence of $3 \mathrm{mg} / \mathrm{kg}$ naloxone or saline. All rats were tested for freezing to the clicker CS. For experimental design, see Table 2. Over $=$ Groups Overexpectation. Ctrl $=$ Groups Control.

and because Groups Control showed very little pre-CS freezing, we considered the possibility that the overexpectation groups showed high and differential levels of freezing that might have contaminated CS freezing very unlikely.

The statistical analysis confirmed the above observations. During Stage 2, rats injected with naloxone displayed significantly more freezing than rats injected with saline, $F(1,14)=12.4, p<$ .01 . However, there was no change in freezing across Day 1 versus Day 2 of Stage 2 training, $F(1,14)=1.7, p>.05$, nor was there any interaction, $F(1,14)<1, p>.05$. In other words, naloxone increased freezing relative to saline during Stage 2 but did not increase any excitatory conditioning that accrued during Stage 2.

On test, there was evidence for overexpectation of fear conditioning because Group Overexpect-Saline showed significantly less freezing than Group Control-Saline, $F(1,28)=5.4, p=.03$. This overexpectation of fear conditioning was prevented by naloxone: Group Overexpect-Naloxone showed significantly more freezing than Group Overexpect-Saline, $F(1,28)=6.5, p=.02$. Naloxone was without effect in the control groups: Group Control-Naloxone did not differ significantly in levels of freezing from Group Control-Saline, $F(1,28)<1, p>.05$.

\section{Discussion}

This experiment has shown that naloxone prevents the overexpectation of Pavlovian fear conditioning. Thus, in Stage 1, rats learned to fear an auditory CS and a flashing light CS by means of separate pairings of each with a footshock US. During Stage 2 the flashing light CS and auditory CS were conditioned in compound with the same US. The outcome of this compound conditioning was overexpectation: a significant reduction in the amount of freezing observed on subsequent presentations of the auditory CS (Group Overexpect-Saline vs. Group Control-Saline). This over- 
expectation was not observed when the Stage 2 compound training occurred under the influence of naloxone (i.e., Group OverexpectNaloxone failed to show overexpectation). Because Stage 2 training occurred under the influence of naloxone, whereas testing occurred in the absence of naloxone, it could be suggested that the failure to see evidence for overexpectation was due to statedependent learning processes. That is, the reduction in conditioning (i.e., overexpectation) failed to generalize from the drug state to the drug-free state. We rejected this possibility for the facilitation of conditioning observed in Experiments 1A and 1B. The difficulty faced by this explanation as applied to the present data is that there was evidence for generalization of learning from Stage 2 to test. Group Overexpect-Saline showed reduced levels of freezing during Stage 2 that were identical to their levels of freezing observed on test. Likewise, Group Overexpect-Naloxone showed the same, and significantly higher levels of freezing than Group Overexpect Saline, during Stage 2 and test. In other words, there was no evidence for a generalization decrement based on drug state in this experiment. Finally, because Group ControlNaloxone received exposures to naloxone but did not otherwise differ from Group Control-Saline, it is unlikely that this evidence for blockade of overexpectation can be attributed to nonspecific actions of opioid receptor antagonism (i.e., naloxone increasing freezing).

\section{General Discussion}

Pavlovian fear conditioning is determined not only by CS-US contiguity, but also by the extent to which conditioning events are predicted or are reliable predictors of their consequences, so that only surprising events and their antecedents are learned about. Although it is widely accepted that the activation of amygdala NMDA receptors detects the CS-US conjunction during Pavlovian fear conditioning, it was previously unknown how such activation is supplemented to allow for the regulation of association formation. Blocking, unblocking, and overexpectation highlight the important role of associative regulation because they show that the contiguous pairings of a CS with a US is insufficient to produce Pavlovian excitatory conditioning and can result, under some circumstances, in significant decrements in conditioning. The present experiments show that opioid receptors regulate Pavlovian association formation. Experiments 1A and 1B replicated prior demonstrations that systemic injections of the competitive opioid receptor antagonist naloxone facilitates the acquisition of Pavlovian contextual and auditory CS fear conditioning. Experiment 2 showed that auditory CS fear conditioning could be blocked by prior shock-reinforced exposures to the context in which that CS was conditioned. This blocking was prevented either by injections of naloxone or increases in US intensity during Stage 2 compound conditioning. Blocking was enhanced by decreases in US intensity during Stage 2 compound conditioning. This enhancement of blocking was prevented by naloxone. Finally, Experiment 3 showed that shocked exposures to an auditory CS in compound with a light CS, when both had previously and separately been paired with shock, significantly reduced the amount of freezing observed on subsequent presentations of the auditory CS. This overexpectation of Pavlovian fear was prevented by naloxone.

The performance of the saline control groups in Experiment 2 are consistent with predictions of the Rescorla-Wagner model
(Rescorla \& Wagner, 1972). The Rescorla-Wagner model states that conditioning proceeds as a function of variations in US processing and formally defines this as the discrepancy between the actual and expected outcome of a conditioning trial $(\lambda-\Sigma \mathrm{V}) . \lambda$ represents the asymptotic strength of association supported by the US, and $\Sigma V$ represents the sum of the associative strengths of all CSs present on that trial. According to Rescorla-Wagner, blocking of CS fear conditioning occurred in Experiment 2 because $\Sigma V$ was larger, and the discrepancy $(\lambda-\Sigma \mathrm{V})$ smaller, during Stage 2 among Group Block-Saline compared to Group Control-Saline. Unblocking of CS fear occurred with the increase in Stage 2 US intensity because $\lambda_{\text {Stage 2 }}>\lambda_{\text {Stage 1 }}$, and so the discrepancy ( $\lambda-$ $\Sigma \mathrm{V}$ ) was larger among Group Unblock Up-Saline compared to Group Control-Saline. Unblocking of CS fear did not occur with the decrease in Stage 2 US intensity because $\lambda_{\text {Stage } 1}>\lambda_{\text {Stage2 }}$ and so the discrepancy $(\lambda-\Sigma \mathrm{V})$ was smaller among Unblock DownSaline compared to Control Down. In fact, the Rescorla-Wagner model predicts that for Group Unblock Down-Saline the discrepancy $(\lambda-\Sigma V)$ should have been negative during Stage 2. In other words, significantly lower levels of performance should have been observed among Group Unblock Down-Saline as compared to Group Control Down. This is precisely the difference between groups that was observed. This reduction in performance is formally similar to extinction and conditioned inhibition according to the Rescorla-Wagner model. The failure to observe unblocking is important because it contrasts with demonstrations of unblocking in appetitive conditioning (e.g., Holland \& Gallagher, 1993) and it cannot be explained by models that rely only on learned variations in CS processing to explain conditioning. For example, Pearce and Hall (1980) predicted that rats in Group Unblock Down-Saline should not have been significantly different from Group ControlDown because the surprising decrease in US intensity in Stage 2 should have reinstated the controlled attentional processing of, and therefore unblocking of fear to, the auditory CS.

Together these observations suggest that naloxone modulated conditioning because it regulated the discrepancy $(\lambda-\Sigma \mathrm{V})$. Fanselow (1998) has suggested one mechanism through which naloxone might have acted to regulate this discrepancy. Exposure to a context previously paired with footshock reduces sensitivity to painful or noxious stimulation (hypoalgesia; e.g., McNally, Gorrisen, Low, \& Westbrook, 1999). This hypoalgesia is achieved, at least in part, by the activation of pathways that descend from the brainstem to the spinal cord dorsal horn to inhibit the ascending transmission of nociceptive information (for review, see McNally, 1999). Fanselow (1998) suggested that the release of opioid peptides in the spinal cord dorsal horn inhibits detection of the shock US and therefore reduces the amount of conditioning based on that US. In other words, during Stage 1 of a blocking experiment, rats learn to fear the context. Subsequent reexposure to the context during Stage 2 elicits an opioid receptor-mediated hypoalgesia that reduces the functional intensity of the footshock US by impairing its detection at the level of the spinal cord dorsal horn. This conditioned hypoalgesia blocks conditioning to the added element, the auditory CS. According to this line of reasoning, naloxone prevented blocking of conditioned fear because it prevented binding of opioid peptides to their receptors in descending pain control pathways and therefore prevented expression of the conditioned response (hypoalgesia) that would have otherwise impaired US processing. The results from Experiments 1A, 1B, and 2 are 
consistent with this model. Moreover, this model is formally similar to the physiological mechanisms of blocking in other conditioning preparations. For example, blocking of the rabbit nictitating membrane (NM) conditioned response occurs because feedback to the inferior olive from the conditioned response generated in interpositus nucleus reduces processing of the shock US (Kim, Krupa, \& Thompson, 1998). It is worth emphasizing that according to this model, naloxone does not act by producing hyperalgesia or affecting a US-related learning parameter (e.g., $\beta$ in the Rescorla-Wagner model). That is, naloxone does not act to increase the aversive or the painful effects of the US beyond those detected in an otherwise naive animal. Rather, naloxone acts selectively to remove the negative feedback mechanism (conditioned hypoalgesia) that regulates US processing and therefore functions to maintain the novelty of US presentations.

A related mechanism for opioid receptor regulation of fear conditioning and the discrepancy $(\lambda-\Sigma \mathrm{V})$ is suggested by the results of Experiment 3. According to the Rescorla-Wagner model, overexpectation of fear conditioning occurred because Stage 1 training increased the separate associative strengths of the clicker and light. During Stage 2 compound training, the summed associative strengths exceeded the amount of learning supported by the US, that is, the discrepancy $(\lambda-\Sigma V)$ was negative. The continued reinforcement of the clicker-light compound therefore reduced the associative strengths of its elements; thus, on test, rats in Group Overexpect-Saline showed significantly less freezing than rats in Group Control-Saline (Wagner \& Rescorla, 1972). Although the performance of Group Overexpect-Saline on test is consistent with the predictions of the Rescorla-Wagner model, their performance during Stage 2 is not. Freezing during Stage 2 showed no evidence for summation of conditioning responding. That is, the amount of freezing elicited by the compound light + clicker CS was no greater than that elicited by either CS alone. This could be consistent with a dissociation between the mechanisms determining levels of conditioned responding and those determining alterations in associative value (e.g., Dickinson et al., 1976; Pearce \& Hall, 1980).

The ability of naloxone to prevent overexpectation of fear is interesting for three reasons. First, models of conditioning that do not rely on the pooled associative strengths of the light and auditory CS (i.e., $\Sigma \mathrm{V}$ ) in determining the discrepancy between the actual and expected outcome of the conditioning trial (e.g., Mackintosh, 1975) cannot easily explain overexpectation. Second, the mechanism for overexpectation offered by the Rescorla-Wagner model is the same as that which mediates extinction and, indeed, conditioned inhibition. That is, overexpectation is an example of inhibitory learning. The reversal of overexpectation by injection of naloxone is consistent with our previous reports that the extinction of fear conditioning is prevented by naloxone (McNally \& Westbrook, 2003). These findings, then, like the impact of naloxone in Group Unblock-Down in Experiment 2, implicate opioid receptors in inhibitory learning during Pavlovian fear conditioning. Finally the mechanism described by Fanselow (1998) struggles to explain the results of Experiment 3. A critical prediction made by the negative feedback model is that naloxone should promote excitatory conditioning to the compound CS, so that freezing should increase significantly across Stage 2 training among naloxonetreated rats as compared to saline treated rats. There was no such evidence for an interaction between groups (Overexpect-Saline vs.
Overexpect-Naloxone) and days. By contrast, if opioids regulate inhibitory conditioning, then naloxone should act simply to prevent overexpectation. That is, Group Overexpect-Naloxone should show higher levels of freezing during Stage 2 as compared to Group Overexpect-Saline (because naloxone prevents overexpectation), but this should not interact with any change across days (because naloxone is not promoting further excitatory conditioning to the compound). This is the pattern of results observed and thus suggests that naloxone acted selectively to prevent the inhibitory conditioning that otherwise would have resulted in overexpectation.

In conclusion, the present experiments have shown for the first time that the opioid receptor antagonist naloxone facilitates the acquisition and prevents the blocking as well as overexpectation of Pavlovian fear conditioning. These experiments show that opioid receptors regulate Pavlovian association formation by regulating the discrepancy $(\lambda-\Sigma \mathrm{V})$ described by Rescorla and Wagner (1972). This regulation might have been achieved by preventing activity in endogenous analgesic mechanisms that otherwise would have reduced the impact of the shock US. According to this possibility, activation of amygdala NMDA receptors represents the temporally contiguous presentations of the CS and US, whereas opioid receptors, at a yet-to-be-identified location, determine the strength of one of these events (the US). This regulation might have additionally been achieved by preventing reductions in associative strength. According to this possibility, opioid receptors, at an as yet unidentified location, provide the inhibition that accrues when the expected US (i.e., $\Sigma$ V) exceeds the actual US (i.e., $\lambda$ ).

\section{References}

Bolles, R. C., \& Fanselow, M. S. (1980). A perceptual-defensiverecuperative model of fear and pain. Behavioral and Brain Science, 3, 291-323.

Campeau, S., \& Davis, M. (1995). Involvement of the central nucleus and basolateral complex of the amygdala in fear conditioning measured with fear-potentiated startle in rats trained concurrently with auditory and visual conditioned stimuli. Journal of Neuroscience, 15, 2301-2311.

Campeau, S., Miserendino, M. J., \& Davis, M. (1992). Intra-amygdala infusion of the $N$-methyl-D-aspartate receptor antagonist AP5 blocks acquisition, but not expression, of fear-potentiated startle to an auditory conditioned stimulus. Behavioral Neuroscience, 106, 569-574.

Davis, M. (1992). The role of the amygdala in fear-potentiated startle: Implications for animal models of anxiety. Trends in Pharmacological Sciences, 13, 35-41.

Dickinson, A., Hall, G. A., \& Mackintosh, N. J. (1976). Surprise and the attenuation of blocking. Journal of Experimental Psychology: Animal Behavior Processes, 2, 313-322.

Fanselow, M. S. (1998). Pavlovian conditioning, negative feedback, and blocking: Mechanisms that regulate association formation. Neuron, 20, 625-627.

Fanselow, M. S., \& Bolles, R. C. (1979). Naloxone and shock-elicited freezing in the rat. Journal of Comparative and Physiological Psychology, 93, 736-744.

Fanselow, M. S., \& LeDoux, J. E. (1999). Why we think plasticity underlying Pavlovian fear conditioning occurs in the basolateral amygdala. Neuron, 23, 229-232.

Goosens, K. A., \& Maren, S. (2001). Contextual and auditory fear conditioning are mediated by the lateral, basal, and central amygdaloid nuclei in rats. Learning \& Memory, 8, 148-155.

Hebb, D. O. (1949). The organization of behavior. New York: Wiley. 
Holland, P. C. (1988). Excitation and inhibition in unblocking. Journal of Experimental Psychology: Animal Behavior Processes, 14, 261-279.

Holland, P. C., \& Gallagher, M. (1993). Effects of amygdala central nucleus lesions on blocking and unblocking. Behavioral Neuroscience, 107, 235-245.

Kamin, L. J. (1968). 'Attention-like' processes in classical conditioning. In M. R. Jones (Ed.), Miami Symposium on the Prediction of Behavior: Aversive stimulation (pp. 9-33). Miami: University of Miami Press.

Kamin, L. J. (1969). Predictability, surprise, attention, and conditioning. In B. Campbell \& R. M. Church (Eds.), Punishment and aversive behavior (pp. 9-31). New York: Appleton-Century-Crofts.

Kamin, L. J., \& Gaioni, S. J. (1974). Compound conditioned emotional response conditioning with differentially salient elements in rats. Journal of Comparative and Physiological Psychology, 87, 591-597.

Khallad, Y., \& Moore, J. (1996). Blocking, unblocking, and overexpectation in autoshaping with pigeons. Journal of the Experimental Analysis of Behavior, 65, 575-591.

Kim, J. J., DeCola, J. P., Landeira-Fernandez, J., \& Fanselow, M. S. (1991). $N$-methyl-D-aspartate receptor antagonist APV blocks acquisition, but not expression, of fear conditioning. Behavioral Neuroscience, 105, 126-133.

Kim, J. J., Krupa, D. J., \& Thompson, R. F. (1998, January 23). Inhibitory cerebello-olivary projections and blocking effect in classical conditioning. Science, 279, 570-573.

Konorski, J. (1967). Integrative activity of the brain. Chicago: University of Chicago Press.

Kremer, E. F. (1978). The Rescorla-Wagner model: Losses in associative strength in compound conditioned stimuli. Journal of Experimental Psychology: Animal Behavior Processes, 4, 22-36.

Lattal, K. M., \& Nakajima, S. (1998). Overexpectation in appetitive Pavlovian and instrumental conditioning. Animal Learning \& Behavior, 26, 351-360.

LeDoux, J. E. (2000). Emotion circuits in the brain. Annual Review of Neuroscience, 23, 155-184.

Mackintosh, N. J. (1975). A theory of attention: Variations in the associability of stimulus with reinforcement. Psychological Review, 82, 276298

Maren, S. (1996). Synaptic transmission and plasticity in the amygdala: An emerging physiology of fear conditioning circuits. Molecular Neurobiology, 13, 1-22.

Maren, S. (2001). Neurobiology of Pavlovian fear conditioning. Annual Review of Neuroscience, 24, 897-931.

McNally, G. P. (1999). Pain facilitatory circuits in the mammalian central nervous system: Their behavioral significance and role in morphine analgesic tolerance. Neuroscience and Biobehavioral Reviews, 23, $1059-1078$

McNally, G. P., Gorrisen, M. C., Low, L.-F., \& Westbrook, R. F. (1999). Effects of contextual cues previously paired with footshock or illness on behavior and pain sensitivity in the rat. Animal Learning \& Behavior, 27, 416-425.

McNally, G. P., \& Westbrook, R. F. (2003). Opioid receptors regulate the extinction of Pavlovian fear conditioning. Behavioral Neuroscience, 117, 1292-1301.
Miserendino, M. J., Sananes, C. B., Melia, K. R., \& Davis, M. (1990, June 21). Blocking of acquisition but not expression of conditioned fearpotentiated startle by NMDA antagonists in the amygdala. Nature, 345 , 716-718.

O’Brien, R. G., \& Kaiser, M. K. (1985). MANOVA method for analyzing repeated measures designs: An extensive primer. Psychological Bulletin, 97, 316-333.

Pearce, J. M., \& Hall, G. (1980). A model for Pavlovian learning: Variations in the effectiveness of conditioned, but not of unconditioned, stimuli. Psychological Review, 87, 532-552.

Petrovich, G. D., Scicli, A. P., Thompson, R. F., \& Swanson, L. W. (2000). Associative fear conditioning of enkephalin mRNA levels in central amygdalar neurons. Behavioral Neuroscience, 114, 681-686.

Ragnauth, A., Schuller, A., Morgan, M., Chan, J., Ogawa, S., Pintar, J., Bodnar, R. J., \& Pfaff, D. W. (2001). Female preproenkephalinknockout mice display altered emotional responses. Proceedings of the National Academy of Sciences, USA, 98, 1958-1963.

Rescorla, R. A. (1970). Reductions in effectiveness after prior excitatory conditioning in the rat. Learning and Motivation, 1, 372-381.

Rescorla, R. A., \& Wagner, A. R. (1972). A theory of Pavlovian conditioning: Variations in the effectiveness of reinforcement and nonreinforcement. In W. F. Prokasy (Ed.), Classical conditioning II: Current research and theory (pp. 64-99). New York: Appleton-CenturyCrofts.

Rogan, M. T., Staubli, U. V., \& LeDoux, J. E. (1997, December 11). Fear conditioning induces associative long-term potentiation in the amygdala. Nature, 390, 604-647.

Sananes, C. B., \& Davis, M. (1992). $N$-methyl-D-aspartate lesions of the lateral and basolateral nuclei of the amygdala block fear-potentiated startle and shock sensitization of startle. Behavioral Neuroscience, 106 , $72-80$.

Tsien, J. Z. (2000). Linking Hebb's co-incidence detection to memory formation. Current Opinion in Neurobiology, 10, 266-273.

Wagner, A. R. (1971). Elementary associations. In H. H. Kendler \& J. T. Spence (Eds.), Essays in neobehaviorism: A tribute to Kenneth W. Spence (pp. 187-213). New York: Appleton-Century-Crofts.

Wagner, A. R., Mazur, J. E., Donegan, J. H., \& Pfautz, P. L. (1980), Evaluation of blocking and conditioning inhibition to a CS signaling a decrease in US intensity. Journal of Experimental Psychology: Animal Behavior Processes, 6, 376-385.

Wagner, A. R., \& Rescorla, R. A. (1972). Inhibition in Pavlovian conditioning: Application of a theory. In M. S. Halliday (Ed.), Inhibition and learning (pp. 301-336). London: Academic Press.

Young, S. L., \& Fanselow, M. S. (1992). Associative regulation of Pavlovian fear conditioning: Unconditional stimulus intensity, incentive shifts, and latent inhibition. Journal of Experimental Psychology: Animal Behavior Processes, 18, 400-413.

Received June 2, 2003

Revision received August 1, 2003 Accepted August 26, 2003 